\title{
Sub-surface structures of ITER-grade W (Japan) and re-crystallized W after ITER-similar low-energy and high-flux D plasma loadings
}

\author{
S. Lindig ${ }^{a, *}$, M. Balden ${ }^{a}$, V.Kh. Alimov ${ }^{b}$, A. Manhard ${ }^{a}$, C. Höschen ${ }^{c}$, T. Höschen $^{a}$, \\ B. Tyburska-Püschel ${ }^{a}$, J. Roth $^{a}$ \\ ${ }^{a}$ Max-Planck-Institut für Plasmaphysik, EURATOM Association, 85748 Garching, Germany \\ ${ }^{b}$ Tritium Technology Group, Japan Atomic Energy Agency, Tokai, Ibaraki 319-1195, Japan \\ ${ }^{c}$ Chair of Soil Science, Department of Ecology and Ecosystem Management, Technical University of \\ Munich, 85350 Freising-Weihenstephan, Germany
}

PACS numbers: $52.40 \mathrm{Hf}, 61.72 \mathrm{Qq}, 61.80 \mathrm{Jh}$

(Some figures in this article are in colour only in the electronic version)

*Corresponding author: Tel.: +49 893299 1262; fax: +49 893299961262.

E-mail address: s.lindig@ipp.mpg.de (S. Lindig)

\begin{abstract}
:
Tungsten is a promising candidate for plasma facing materials in fusion reactors. In this work two types of $W$ specimens were investigated: i) sintered and forged tungsten (ITER grade Japan, grain sizes 2-100 $\mu \mathrm{m}$ elongated normal to surface) and ii) the same W grade, but after additional re-crystallisation (at $2073 \mathrm{~K}$, grain size $\sim 50 \mu \mathrm{m}$ ). The samples were exposed to deuterium with an ion energy of $38 \mathrm{eV} / \mathrm{D}$, fluence of $10^{27} \mathrm{D} / \mathrm{m}^{2}$, and flux of $\sim 10^{22} \mathrm{D} / \mathrm{m}^{2} \mathrm{~s}$ in a plasma generator at elevated temperatures $(320 \mathrm{~K}-700 \mathrm{~K})$. The $\mathrm{D}$ retention (determined by thermal desorption spectroscopy and nuclear reaction analysis) of both sample types is compared. The samples were analysed with scanning electron microscopy combined with a focused ion beam for iterative cross-sectioning to obtain three-dimensional (3D) data of the subsurface. Electron backscattered diffraction was applied to determine the grain orientation and deformation. First Nano-secondary ion mass spectroscopy investigations were performed on a $D$ loaded sample to analyse the lateral accumulation of $H / D$ on the surface.
\end{abstract}

\section{Introduction}

Tungsten is a promising candidate for a plasma facing material in the main chamber and also for divertor areas in fusion reactors as ITER and DEMO. The melting point is high enough and the erosion of this high- $Z$ material by plasma is acceptable low. The deuterium (D) retention (respectively Tritium (T)) is intensively investigated by many groups [1-3]. But further clarification is needed on how and under which conditions $\mathrm{D}$ enters the material and where $\mathrm{D}$ is mainly accumulated [4]. The absolute $\mathrm{D}$ and $\mathrm{T}$ retention, respectively, in $\mathrm{W}$ seems to be tolerable for next-generation nuclear fusion devices such as ITER and DEMO [5]. In ITER hydrogen loading on the wall tiles in the main chamber $(\sim 450 \mathrm{~K})$ is expected to be about $10^{21} \mathrm{D} / \mathrm{m}^{2} \mathrm{~s}$ with $\sim 200 \mathrm{eV}$, whereas the loading on the divertor components $(\sim 750 \mathrm{~K})$ is estimated to be more than $10^{24} \mathrm{D} / \mathrm{m}^{2} \mathrm{~s}$ with $\sim 15 \mathrm{eV}$ and a fluence of about $10^{26} \mathrm{D} / \mathrm{m}^{2}$ per ITER pulse [6].

Many groups have investigated a variety of $\mathrm{W}$ materials made by using different machining processes and material grades, various polishing procedures, different grain sizes, dislocation densities and annealing or re-crystallisation processes. The D loadings conditions also differ, because each group uses different plasma experiments, energies, fluences, fluxes, etc. Therefore, it is difficult to get a consistent picture of the complex behaviour and the formation of surface structures after $\mathrm{D}$ bombardment of $\mathrm{W}$ in dependence with respect to the experimental parameters and the material properties [7-10].

In this work, ITER-grade $\mathrm{W}$ material made in Japan with elongated grains perpendicular to the surface is exposed to low energy D plasma similar to ITER with a flux of $10^{22} \mathrm{D} / \mathrm{m}^{2} \mathrm{~s}$ at different temperatures ranging from about 320 up to $720 \mathrm{~K}$ with an energy of 38 $\mathrm{eV} / \mathrm{D}$ and fluences up to $10^{27} \mathrm{D} / \mathrm{m}^{2}$. The main issue is the investigation of the sub-surface region of the loaded specimens by focused ion beam (FIB) crosssectioning and scanning electron microscopy. This work was directly motivated by the result of a previous work [11] that uses the same method but deals with re-crystallized W having large grains of 20- 
$200 \mu \mathrm{m}$ under exactly identical plasma loading condoitions. In that work [11], investigations of recrystallized W using FIB cross-sectioning show strong variations of blister-like structures and assumed deformations (based on contrastvariations in SEM images) in sub-surfaces areas depending on temperature. The temperature depends on $\mathrm{D}$ retention seems to show correlations to the strong variations of surface strucutres. Next, in this work, the surface changes of ITER-grade $\mathrm{W}$ are analysed and compared with re-crystallized W from [11] after identical D loading, resulting in totally different structures but similar $\mathrm{D}$ retentions. The $\mathrm{D}$ retention in $\mathrm{W}$ is analysed by nuclear reaction analyse (NRA) and thermal desorption spectroscopy (TDS) [12,13].

Additional experiments are performed in this work to solve the remaining open questions. Evaluable measurements of grain deformation are carried out by electron backscattered diffraction (EBSD) to clarify the contrast variation in the SEM images from the recrystallized $\mathrm{W}$ material. The reason for these strong deformations seems to be transient supersaturation during plasma loading [11].

Therefore, a urther experment with constant fluences but different fluxes was performed on the recrystallized W, which confirmed the assumption. In this context, for understanding the formation process of these structures, it is important to know where the deuterium/hydrogen is accumulated: at grain boundaries, in grains, at dislocations or in cavities and micro-pores. Some recent publications have reported that the gas content and pressure of blisters with diameters down to $5 \mu \mathrm{m}$ can be determined $[9,10]$. Therefore, in this work, first studies were carried out to localize hydrogen and deuterium on the surface laterally by secondary ion mass spectrometry (SIMS) on the nano-scale, i.e. the nanoSIMS technique. A recrystallized W sample was used that has a low and well-defined grain dislocation density. In principle, it can be shown that it is possible to map H/D on grain boundaries and detect micro-pores smaller than about $100 \mathrm{~nm}$ filled by gas.

\section{Experimental}

Two types of $\mathrm{W}$ materials were investigated: i) rolled, sintered, and forged tungsten with a mirror-finish polished surface and elongated grain sizes of about 2$100 \mu \mathrm{m}$ normal to the sample surface (ALMT Corp., Japan), also called ITER-grade and ii) the same W grade but with additionally re-crystallisation at $2070 \mathrm{~K}$ for $1 \mathrm{~h}$ under $\mathrm{H}$ atmosphere (grain sizes 20-200 $\mu \mathrm{m}$ ). For a better understanding of the behaviour of materials under D bombardment, the re-crystallized W was used because of well-defined material conditions such as a clean and undisturbed surface and low dislocations density and plastic strain.

The specimens were exposed to a deuterium plasma beam from a linear plasma generator [14]. The plasma beam consists mainly of $\mathrm{D}_{2}^{+}$(over $80 \%$ ). The main impurity in the plasma was oxygen with a concentration less than 1 ppm [14]. The impact energy per $\mathrm{D}$ atom was chosen as $38 \mathrm{eV}$ by applying a bias voltage to the $\mathrm{W}$ specimen $(-80 \mathrm{~V})$ and a plasma potential (about $-4 \mathrm{~V}$, measured by a Langmuir 2 probe). The incident deuterium flux was $10^{22} \mathrm{D} / \mathrm{m} \mathrm{s}$. The accumulated fluence on the investigated samples was $10^{27} \mathrm{D} / \mathrm{m}^{2}$. For investigating the effect of supersaturation by varying the ion flux, an ion energy of 96 $\mathrm{eV} / \mathrm{D}$, a fluence of $10^{26} \mathrm{D} / \mathrm{m}^{2}$, and fluxes of $10^{21} \mathrm{D} / \mathrm{m}^{2} \mathrm{~s}$ and $1.25 \times 10^{22} \mathrm{D} / \mathrm{m}^{2} \mathrm{~s}$ were applied. The energy must be changed because of concerns regarding stability of the plasma generator at lower fluxes. For comparison, a higher energy was also used for the standard flux of $10^{22} \mathrm{D} / \mathrm{m}^{2} \mathrm{~s}$ and it is shown that the elevated energy does not influence the sub-surface structures.

The main parameter that was changed in the experimental series was the sample temperature during plasma exposure, which was varied between 320 and $720 \mathrm{~K}$. The exposure temperature was measured with a thermocouple pressed onto the rear side of the specimen [15]. The temperature was adjusted by varying the thermal contact of the specimen to the target holder in order to change the effective cooling of the plasma-heated specimen.

The $\mathrm{D}$ retention of these specimens was determined by TDS and NRA using the reaction $\mathrm{D}\left({ }^{3} \mathrm{He}, \mathrm{p}\right)^{4} \mathrm{He}$ by scanning the ${ }^{3} \mathrm{He}$ energy from $690 \mathrm{keV}$ up to $4 \mathrm{MeV}$. The results are presented in $[12,13,16]$.

The surface topography and the 3D morphology of the plasma-exposed tungsten were analysed by SEM. The 3D-information was obtained by sequential crosssectioning with a FIB and by SEM-imaging. The device was used, HELIOS NanoLab 600 (FEI), combines both and allows an automated sequence of cross-sectioning and imaging. Because the distance between images is precisely controlled, the 3D structures can be evaluated and displayed as a movie. The angle between the ion and electron beam is $52^{\circ}$. The surface normal was aligned parallel to the ion beam for the cross-sectioning. The $\mathrm{Ga}$ ions had an impacting energy of $30 \mathrm{keV}$ and the current of the ion beam was varied between 1 and $25 \mathrm{nA}$. The SEM images were typically taken using a $5 \mathrm{keV}$ electron beam. To reduced artefacts of the cutting process (e.g. curtaining effect), the area of interest was coated insitu with a Pt-C film prior to the cutting. Thereby the introduced precursor gas $\left(\mathrm{C}_{9} \mathrm{H}_{16} \mathrm{Pt}\right)$ was cracked locally by scanning one of the two beams over a selected area.

In addition, the observed blister-like structures are correlated to the crystallographic orientation of the individual grains. The grain orientation was determined by EBSD. A $20 \mathrm{keV}$ electron beam with an incident angle of $70^{\circ}$ to the normal of the analysed surface area was typically used for the EBSD analysis with the Nordlys II-detector (HKL), and Channel 5 analysis software (HKL).

In order to determine the lateral hydrogen and deuterium distributions, especially the proposed accumulation of $\mathrm{D}$ at grain boundaries, first analyses were performed with with the device NanoSIMS $50 \mathrm{~L}$ from Cameca on a D-exposed re-crystallized W sample. D plasma was used with an energy of $38 \mathrm{eV} / \mathrm{D}$, lower fluence of $6 \times 10^{24} \mathrm{D} / \mathrm{m}^{2}$ and a lower flux of 0.9 
$\mathrm{x} 10^{20} \mathrm{D} / \mathrm{m}^{2} \mathrm{~s}$ than those for the other samples investigated in this paper, in order to avoid strong deformations in the surface layer (the plasma device we used was PlaQ from IPP Garching). For NanoSIMS, $\mathrm{Cs}^{+}$-ions of about $16 \mathrm{keV}$ were applied to sputter the surface layer and create negative secondary ions which are detected by a multi-channel magnetic sector field mass spectrometer and the created secondary electrons (SE) are used for imaging.. The pressure in the sample chamber was typical $10^{-10} \mathrm{mbar}$. A pre-sputter fluence of typically about $10^{20} \mathrm{Cs} / \mathrm{m}^{2}$ was applied to remove surface contamination such as oxide layers and also to saturate the surface matrix for stabilizing the secondary ion generation.

\section{Results and Discussion}

\section{1. D retention}

The data on $\mathrm{D}$ retention in re-crystallised $\mathrm{W}$ and ITER-grade W measured by NRA and TDS $[12,13,16]$ are shown in Fig. 1. The surprising result is that the total D retention measured by TDS is in both sample types nearly identical over the whole range of applied temperatures, although these $\mathrm{W}$ materials differ strongly in dislocation density, grain sizes, and accordingly grain boundary density. It is pertinent to note that the $\mathrm{D}$ retention within the sub-surface region up to a depth of about $7 \mu \mathrm{m}$ (the analysing range of NRA) in the re-crystallised $W$ is higher by a factor of about 2 than that in the ITER-grade $\mathrm{W}$ for temperatures in the range between $\sim 350$ and $\sim 650 \mathrm{~K}$. That means that the re-crystallised $\mathrm{W}$ accumulates twice as much $\mathrm{D}$ into the near-surface region, probably in blister-like structures such as pores and cracks, which are mainly formed in this temperature range. The $\mathrm{D}$ in ITER-grade $\mathrm{W}$ may diffuse fast along the grain boundaries deeper in the bulk. At temperatures more than $700 \mathrm{~K}$ the retention of recrystallized $\mathrm{W}$ is lower than that of ITER-grade W. It could be speculated that the diffusion through the grains is higher than that in ITER-grade, because in ITER-grade $\mathrm{W}$ the grains are smaller and the grain boundary density is clearly higher. The effect of the boundaries as a diffusion barrier becomes dominant and rduces the diffusion.

\section{2. Surface and Sub-Surface Morphology}

Re-crystallised W shows a strong dependence of the D-induced surface and sub-surface morphology under exposure to the low energy and high flux D plasma. More details about these structures can be found in [11]. At an exposure temperature of $320 \mathrm{~K}$ only a few scattered blister-like structures are observed with associated small cracks in the sub-surface (Fig. 2a,b). Many irregularly shaped structures with strong deformations, intra-granular cracks and lattice bending appear at about 400-500 K (see a similar sample in Fig $5 \mathrm{a})$. However, at $600 \mathrm{~K}$ the grains remain apparently undamaged, but material is moved out along a
$\{100\}<111>$ slip system $[17,18]$ forming large extrusions with an associated pore at the grain boundary next to the surface (Fig. 3a,b). No visible surface changes appear at even higher temperatures of about $700 \mathrm{~K}$.

In contrast, the polycrystalline ITER-grade $\mathrm{W}$ shows a totally different behaviour. The blister-like structures are visible over the whole temperature range from 320 up to $700 \mathrm{~K}$. The size and the number of structures per area remain nearly constant, also at about $700 \mathrm{~K}$, where re-crystallised W shows no blisters. The blisterassociated pores arise very frequently at the interface between the bulk material and the 0.3-1 $\mu \mathrm{m}$ thick surface layer, which is strongly distorted by the mechanical polishing process (Fig. 2c-e and Fig 3c-e). This distorted layer as in fig. $2 \mathrm{~d}$ and e, but without blisters and cracks already exists for the unirradiated sample [13], not shown in this work. The Bending of the crystal lattices and cracks like that observed in recrystallised W at about 400-500 K could not be seen. Also, extrusions along slip systems are typically not visible. Only in a single region, three small extrusions were found for a relatively large grain $(\sim 25 \mu \mathrm{m})$. It is pertinent to mention that this grain has no visible polishing damage on the surface. An explanation could be that during $\mathrm{D}$ irradiation the transient supersaturation causes very high stress in the upper area of the grain, which can be reduced by moving dislocations and material at temperatures above the DBTT (ductile to brittle transition temperature) $[19,20]$. The pore is created at the weakest point, e.g., the grain boundary. If the surface layer is disturbed like in the ITER-grade specimen, then the interface of this layer is the weakest point and the stress will be reduced by cracking there and inflating into a blisterlike structure by the transiently supersaturated deuterium.

The blisters are very probably gas filled, because of the following: for stepwise cross-sectioning slice by slice, the surface must be covered by a Pt-_C mixed protection layer. The positions of some blisters were marked by FIB-made trenches at a distance of about 2 $\mu \mathrm{m}$ to the blister to find them again easily. During marking of the blisters, they relaxed and collapsed partly, very probably by out-gassing. A similar behaviour of blisters is described in [9], the opening by FIB must be directly of the blister cap itself. In contrast to [9], the surface structures also relax if the trench is microns away. This indicates that the distorted polished surface layer offers a crack network at least around the blister which is connected with the blister. The marker trenches are shown in the crosssections in Fig. 2d,e. Other analysed regions were marked with very flat trenches, which do not achieve the depth level of the crack system. In this case the blisters did not collapse.

It is also remarkable that for the blisters on rolled polycrystalline $\mathrm{W}$ with elongated grains parallel to the surface, the blister cap is often thicker than $1 \mu \mathrm{m}$, e.g. [9]. For the ITER-grade $\mathrm{W}$ with a damaged layer due to the polishing procedure, the blister cap thickness never exceeds $1 \mu \mathrm{m}$. 


\section{3. Flux dependent effects for re-crystallized W}

Two re-crystallized $\mathrm{W}$ were exposed at $490 \mathrm{~K}$ to a low energy (96 eV/D) deuterium-plasma with an identical ion fluence of $10^{26} \mathrm{D} / \mathrm{m}^{2}$ but different ion fluxes of $1 \times 10^{21} \mathrm{D} / \mathrm{m}^{2} \mathrm{~s}$ and $1.25 \times 10^{22} \mathrm{D} / \mathrm{m}^{2} \mathrm{~s}$. The resulting surfaces are shown in (Fig. 4). The specimen exposed to the lower flux shows large blister-like structures (extrusions) with cavities in the sub-surface region like in (Fig. 3a,b). Typically, ther are no or only a small number of cracks and deformations in the nearsurface region. The specimen exposed to a 12-times higher flux shows slightly smaller extrusions, but also a number of small irregular blister-like structures, which indicate a strongly deformed and cracked subsurface layer. A cross-section of one grain in this region is shown in Fig. 5. An EBSD-map of this crosssection shows the colour-coded deviation of the orientation of this grain (the second Euler angle). It could be confirmed that the grain is strongly plastically bent by about $5^{\circ}$ over a distance of $1 \mu \mathrm{m}$ typically (Fig. 5c,d). This is very probably a residual fingerprint of the extreme stress conditions during the transient supersaturation.

\section{4. Hydrogen localization}

First nano-SIMS experiments were executed to determine and visualize the lateral accumulation of deuterium/protium in the near-surface layer of a rolled and re-crystallized $\mathrm{W}$ sample loaded with a D plasma at $370 \mathrm{~K}\left(6 \times 10^{24} \mathrm{D} / \mathrm{m}^{2}, 0.9 \times 10^{20} \mathrm{D} / \mathrm{m}^{2} \mathrm{~s}, 38 \mathrm{eV} / \mathrm{D}\right)$. This loading was used to get a well-defined sample, because the ingrain dislocation density is low by recrystalization and the surface region is not or only very weakly demaged by low flux and fluence loading. There were no blisters created and no grains deformed or cracked. Comparing the SEM image (Fig 6a) and mass-1 image (Fig 6b) clearly shows the accumulation of hydrogen at grain boundaries; pay attention especially to the right upper grain in panel (b). A geometric effect as artefact can be excluded, because other masses $(2,12,16$, not shown) do not show similar behaviour. The D signal does not show an accumulation, probably because the sample was already saturated with $\mathrm{H}$ before $\mathrm{D}$ loading. An isotope exchange is not expected at these loading parameters. Self-re-deposition of hydrogen from the residual gas in the vacuum during the scanning process could be possible, but nevertheless these results show that it is in principle possible to visualize the $\mathrm{H}$ and $\mathrm{D}$ accumulation separately and the sensivity is high enough, but more investigations (e.g. with unloaded W) are necessary to learn more about the measured effects and accuracy. Another surface area is displayed in Fig. 6c which shows permanent and transient spots on the surface in the $\mathrm{D}^{-}$-signal but not for $\mathrm{H}^{-}$. The mass-1 signal shows at both spots a strongly reduced emission, probably because the emitted D suppresses the formation of $\mathrm{H}^{-}$ions. The mass-2 signal of each SIMS scan is plotted against the scan number (respectively time) in Fig. 6d. A D-burst is clearly visible and its decay is typical for the outgassing of a small pore. The pore has an estimated diameter of about $100 \mathrm{~nm}$. This means that the gas-filled pores can be identified and detected. Therfore the technique of gas-filled blister detection in [9], which is possible for blister diameters down to about $5 \mu \mathrm{m}$, can be extended up to at least $100 \mathrm{~nm}$. However, the quantitative evaluation of gas filling will be very difficult because of a number of uncertainties.

\section{Conclusion}

Identical plasma $\mathrm{D}$ loadings at various sample temperatures from 320 up to $720 \mathrm{~K}$ show totally different morphological evolutions on re-crystallized $\mathrm{W}$ compared to mechanical polished ITER-grade W. Therfore material properties (such as surface quality, dislocation density, grain sizes and grain orientations) play an essential role in the formation of surface structures and the amount of retained $\mathrm{D}$ in the nearsurface region of about $7 \mu \mathrm{m}$. The re-crystallized W forms more and larger blister-like structures with a large cavity volume than the ITER-grade W. This is probably the reason, why the $\mathrm{D}$ content in the nearsurface layer is two times higher in re-crystallised material for elevated temperatures until $700 \mathrm{~K}$. The total $\mathrm{D}$ retention is nearly identical in both types of investigated materials, re-crystallized $\mathrm{W}$ and ITERgrade $\mathrm{W}$ (Japan), although the bulk properties are different.

The transient supersaturation during plasma loading depends strongly on the $\mathrm{D}$ flux. At higher fluxes $\left(10^{22}\right.$ $\mathrm{D} / \mathrm{m}^{2} \mathrm{~s}$ ) the supersaturation can damage the sub-surface layer up to 5 or $10 \mu \mathrm{m}$ in depth by cracking and deformation of the grains in the re-crystallized $\mathrm{W}$. The plastic bending and deformation of the grains can be three dimensionally evaluated. The quantitative data could be used to calculate or simulate the behaviour of the material under supersaturation. In ITER-grade $\mathrm{W}$ blisters and crack systems build up between bulk and the mechanical damaged layer. Deformations in the damaged layer and bulk by $\mathrm{D}$ exposure can not be measured. The effects of surface finishing on blistering behaviour and $\mathrm{D}$ retention is reported in the literature [21,22]. Our observation of the damaged layer due to the polishing procedure and its correlation to blistering confirm the necessity for more systematic studies of the effect of surface morphology on blistering and D retention. Definitely, the surface finish must be taken into account by comparing results from different experimental groups.

In ITER fluxes even higher than $10^{22} \mathrm{D} / \mathrm{m}^{2} \mathrm{~s}$ are possible and expected: Therefore, it could be assumed that possibly the blisters explode or the surface layer delaminates. The effect of such morphologies on the total $\mathrm{D}$ retention could not be predicted, i.e., the correlation between total D retention and surface morphology is by far not trivial. Furthermore, dedicated experiments with even higher ion fluxes are necessary in order to examine the potential of damage by high fluxes. Probably, these higher fluxes lead to a partial disintegration of the surface. This would 
increase the erosion of $\mathrm{W}$ and would be a source for producing dust with all its correlated safety issues [5, 23,24].

In order to understand and predict the $\mathrm{D}$ retention in $\mathrm{W}$, the trapping sites and the distribution of $\mathrm{D}$ in $\mathrm{W}$ must be known. The first results with the nano-SIMS technique give the proof of principle that hydrogen and deuterium bonded at grain boundaries could be investigated with high enough lateral resolution. Also the sensitivity to detect $\mathrm{H}$ and $\mathrm{D}$ is high enough. Further, gas-filled pores down to at least $100 \mathrm{~nm}$ in diameter can be detected and the gas can be determined. But the technique must be further developed. In addition, with this technique it is possible to analyse also deformed and bended zones in sub-surface region regarding their $\mathrm{D}$ distribution. These data is necessary to obtain a better understanding of the formation process under supersaturation of the bending, cracking, and blistering of $\mathrm{W}$.

In summary, further investigation of the effective diffusion along grain boundaries or through the bulk of grains, and the determination of the accumulation of hydrogen are needed. Furthermore, technical surfaces (strongly distorted surfaces) should be analysed. Dedicated experiments, e.g., with even higher ion fluxes are necessary. Combining finite element simulations of the mechanical loading and stress condition during the D transient supersaturation with mutated mechanical material properties could help in obtaining a more complete picture of the behaviour of the material under fusion reactor-like deuterium loading conditions.

\section{$\underline{\text { References }}$}

[1] Skinner CH et al. 2008 Fusion Sci. Technol. 54 891

[2] Causey RA 2002 J. Nucl. Mater. 30091

[3] Causey RA, Venhaus T J 2001 Phys. Scr. T94 9

[4] von Toussaint U et al. 2011, Phys. Scr.T145 014038

[5] Roth J et al. 2009 J. Nucl. Mater. 3901

[6] Roth J et al. 2008 Plasma Phys. Control. Fusion 50103001

[7] Manhard A et al. 2011 J. Nucl. Mater. 415 S632

[8] Nishijima D et al. 2005 Nucl. Fusion 45669

[9] Balden M et al. 2011 J. Nucl. Mater. 41469

[10] Manhard A et al. 2011 Phys. Scr.T145 014037

[11] Lindig S et al. 2009 Phys. Scr. T138 014040

[12] Alimov VK et al. 2011 J. Nucl. Mater. 417572

[13] Alimov VK et al. $2011 \mathrm{~J}$. Nucl. Mater. at press doi: 10.1016/j.jnucmat.2011.11.003

[14] Luo G-N et al. 2004 Rev Sci Instrum. 754374

[15] Luo G-N et al. 2006 Fusion Eng.Des. 81957

[16] Alimov VK et al. 2009 Phys. Scr. T138 014048

[17] Lassner E and Schubert WD 1999 Tungsten (New York: Kluwer Academic) p 257

[18] Yalcinkayal T et al.2008 Modelling Simul. Mater.Sci.Eng. 16085007

[19] Gumbsch P et al. 1998 Science 2821293

[20] Giannattasio A et al. 2007 Phys. Scr. T128 87

[21] Nishijima D et al. 2005 Nucl. Fusion 45669

[22] Sugiyama K 2011 Phys. Scr. T145 014023

[23] Scharpe J P et al. 2002 Fusion Eng. Des. 63/64 153

[24] Denkevits A 2010 Fusion Eng. Des. 851059 
Figures printed: black \& white I electronic version: coloured

Figure 1

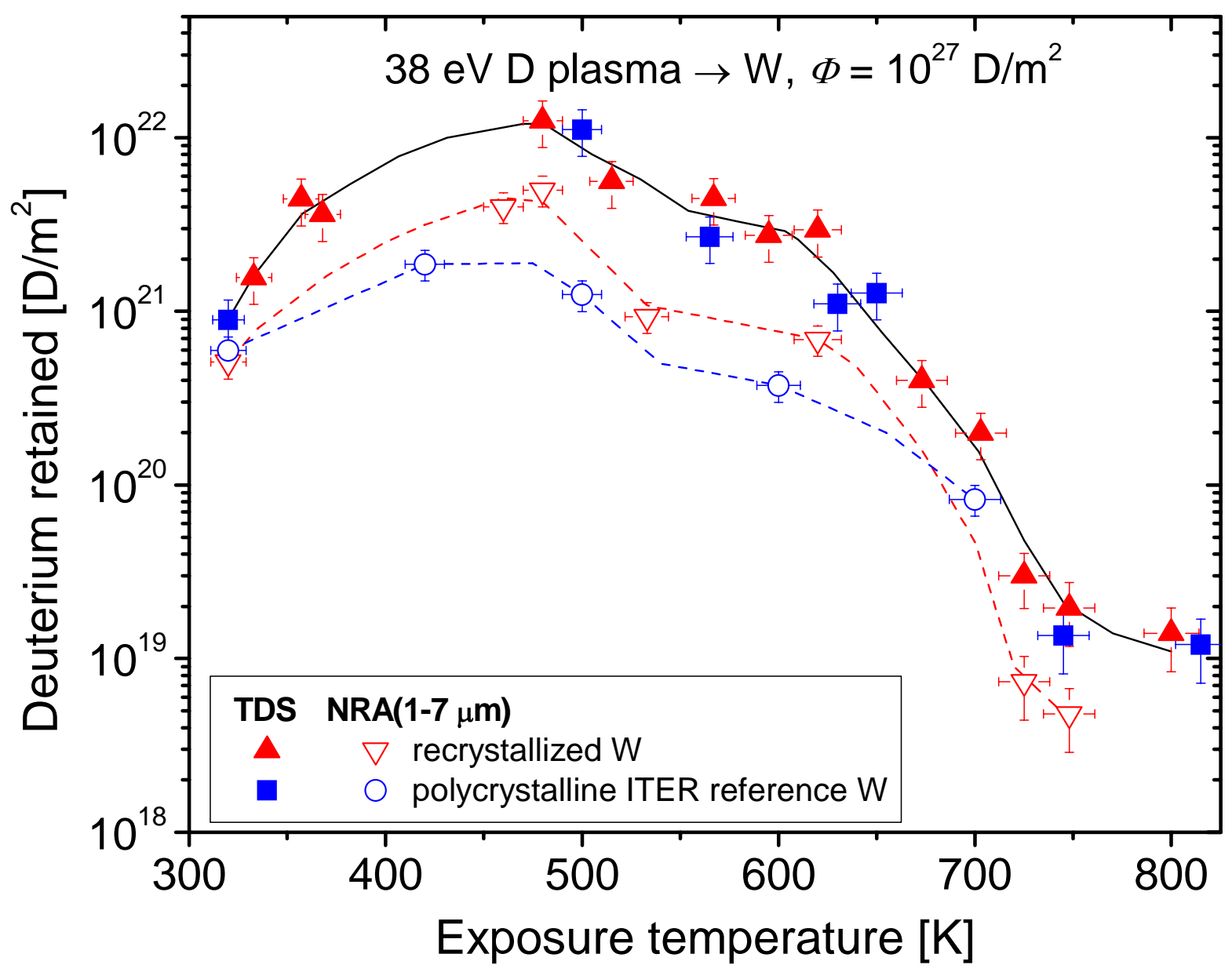

Fig. 1 D retention in $W$ samples as a function of loading temperature. The TDS data show the total $D$ content of the specimens. However, the NRA analyzes determine the $\mathrm{D}$ content up to a specimen depth of $7 \mu \mathrm{m}$ only. 


\section{Figure 2}
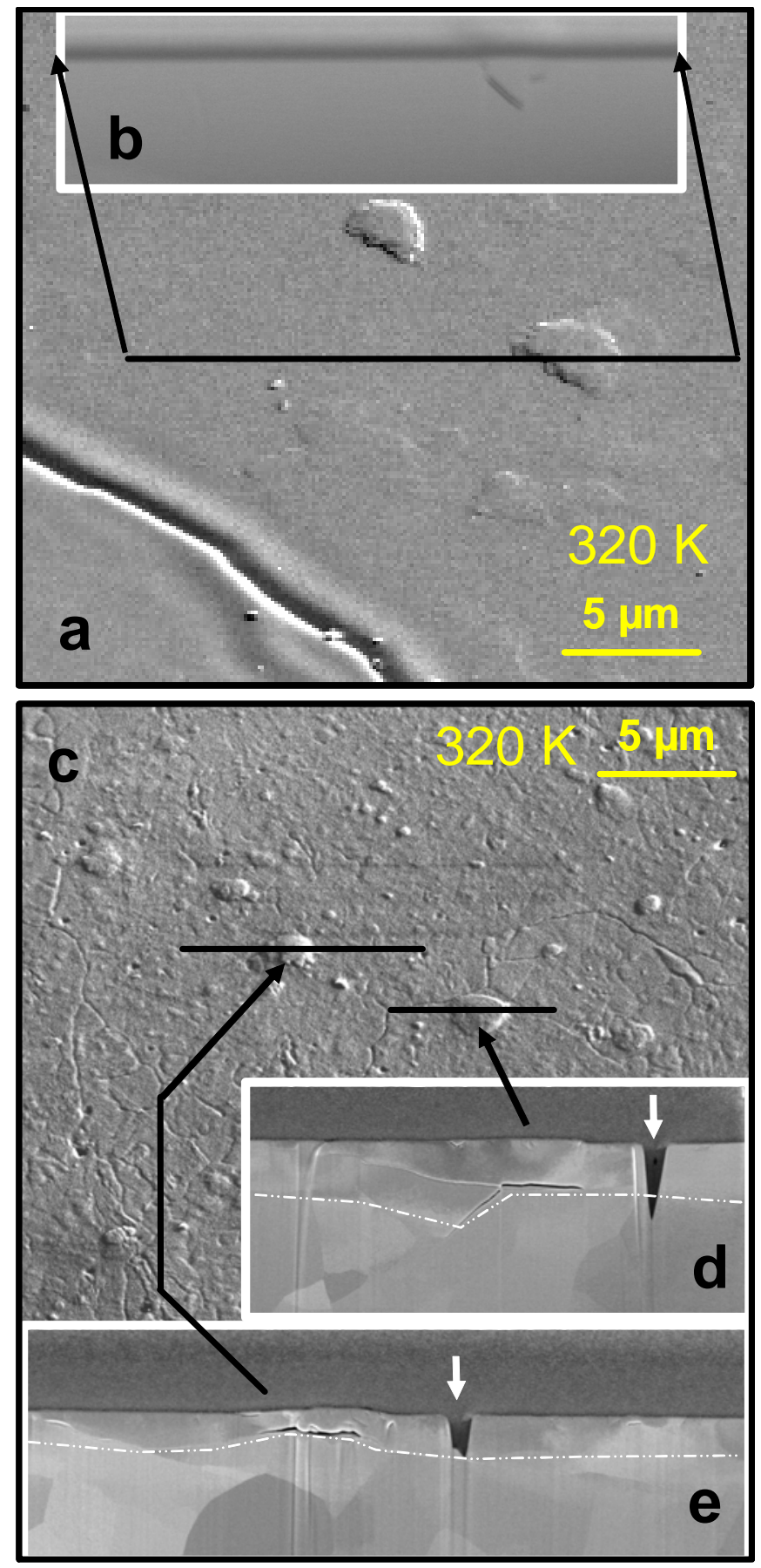

Fig 2 Samples loaded with D at 320 K. a) Re-crystallised W shows only a few scattered blisters with small cracks in the subsurface. b) Cross-section at the marked line in a) with protection layer on the surface. c) ITER-grade W shows many small blisters on the surface. d) and e) Cross-sections at the marked lines in c). The subsurface pores of the blister occur often at the interface between mechanical damaged zone caused by polishing (marked by white line) and the undisturbed bulk material. The blisters were marked by a FIB trench (white arrows). The blisters relaxed by out-gassing after cutting of these trenches and became flat. 


\section{Figure 3}

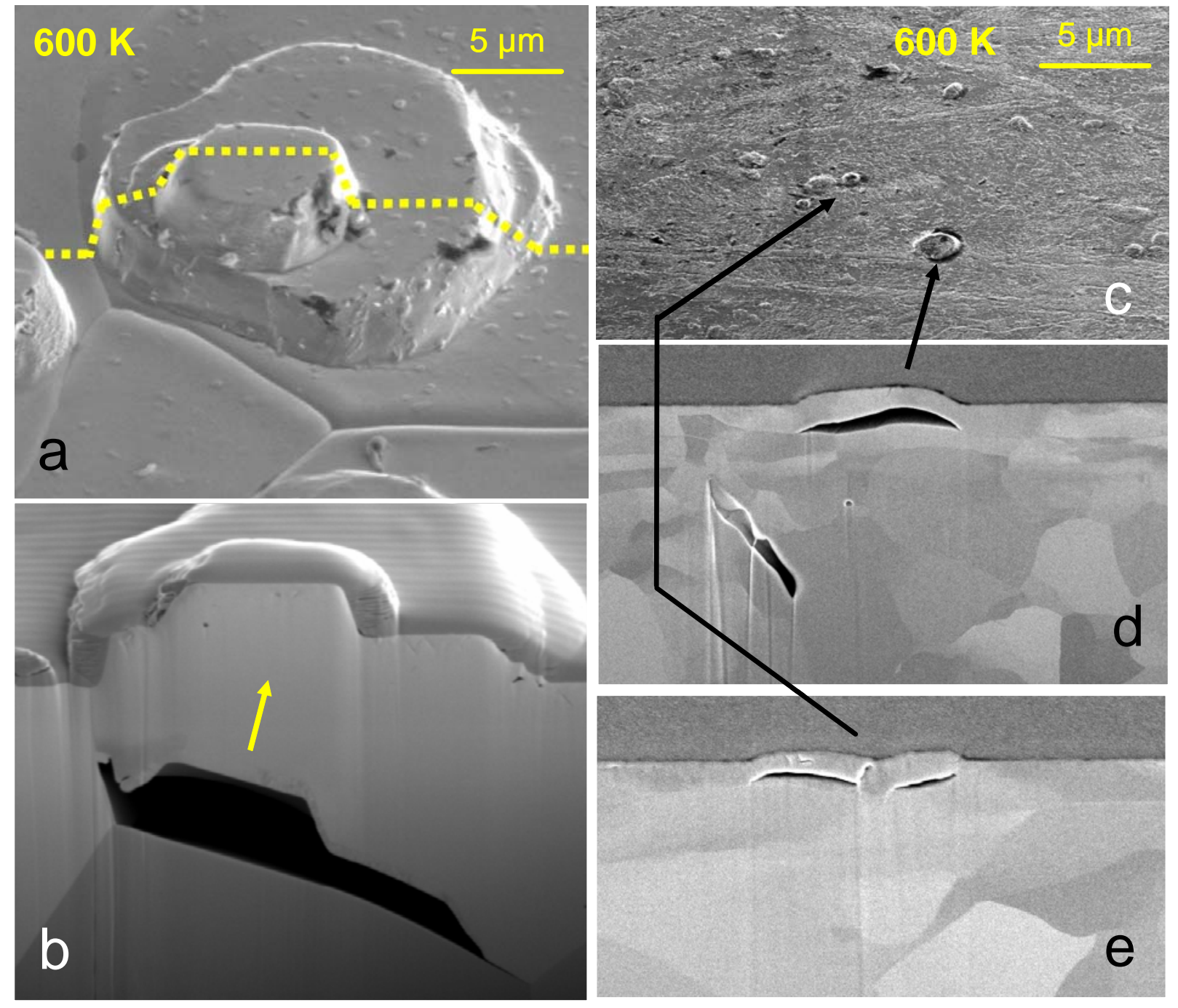

Fig 3 Samples exposed to $\mathrm{D}$ at $600 \mathrm{~K}$ a) Extrusions on the surface of re-crystallised $W$ depend on the grain orientation. b) Cross-section at the marked line in a). The arrow shows the gliding direction along the slip system $\{110\}<111>$. c) Surface of ITER-grade $\mathrm{W}$ with blisters. d) and e) Cross-sections of the marked blisters. The pores below the blister are horizontal cracks at the interface between the bulk and the zone damaged by mechanical polishing. The vertical crack in d) inside the bulk material is caused by the manufacturing process before $D$ loading. 


\section{Figure 4}
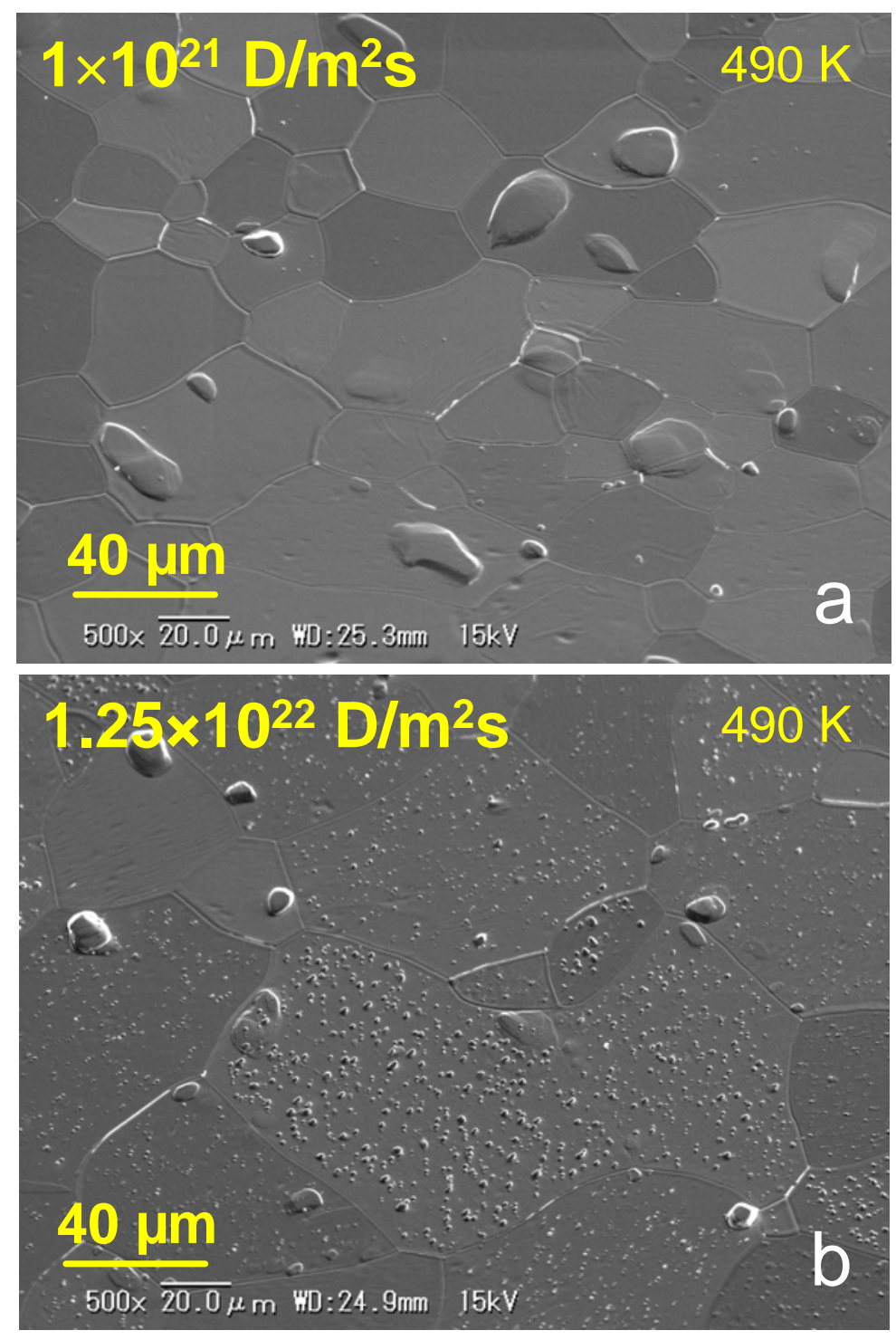

Fig 4 Micrographs of the surface of re-crystallised $W$ exposed to a D fluence of $10^{26}$ $\mathrm{D} / \mathrm{m}^{2}$ with $96 \mathrm{eV} / \mathrm{D}$ at $490 \mathrm{~K}$ a) at an ion flux of $1 \times 10^{21} \mathrm{D} / \mathrm{m}^{2} \mathrm{~s}$ and $\mathbf{b}$ ) at an ion flux of $1.25 \times 10^{22} \mathrm{D} / \mathrm{m}^{2} \mathrm{~s}$. The surface in b) shows large blister-like extrusions and many small irregular structures which indicate a deformed and cracked subsurface region, however the surface in a) shows larger blister-like extrusions, but no small irregular structures. 
Figure 5

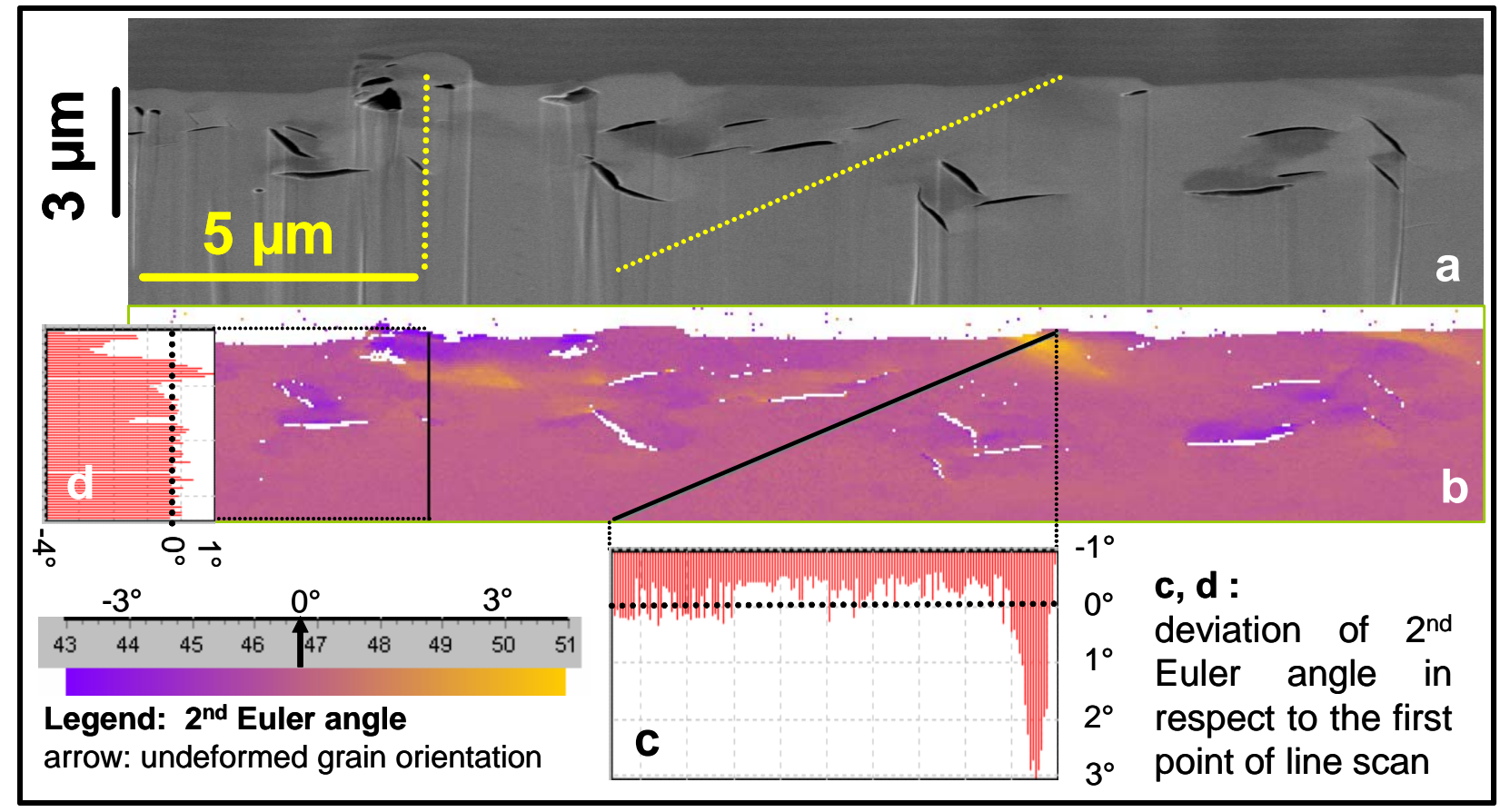

Fig 5 a) SE-micrograph cross-section (26 tilted to sample surface) of re-crystallized W loaded with $5 \times 10^{26} \mathrm{D} / \mathrm{m}^{2}, 400 \mathrm{~K}, 10^{22} \mathrm{D} / \mathrm{m}^{2} \mathrm{~s}$. The subsurface area is deformed as it can be deduced from the orientation contrast and cracked by transient supersaturation. The sample surface is coated by a protective $\mathrm{Pt} / \mathrm{C}$ mixed layer before FIB cutting. b) EBSD orientation map of the deformations in the grain shown in a). The second Euler angle of the lattice orientation is colour coded, which show the angular deviation of the grain orientation. The original orientation (undisturbed region) of this grain is marked with an arrow in the colour legend. c) and d) Line scans along the marked lines relative to the second Euler angle at their starting point. 


\section{Figure 6}

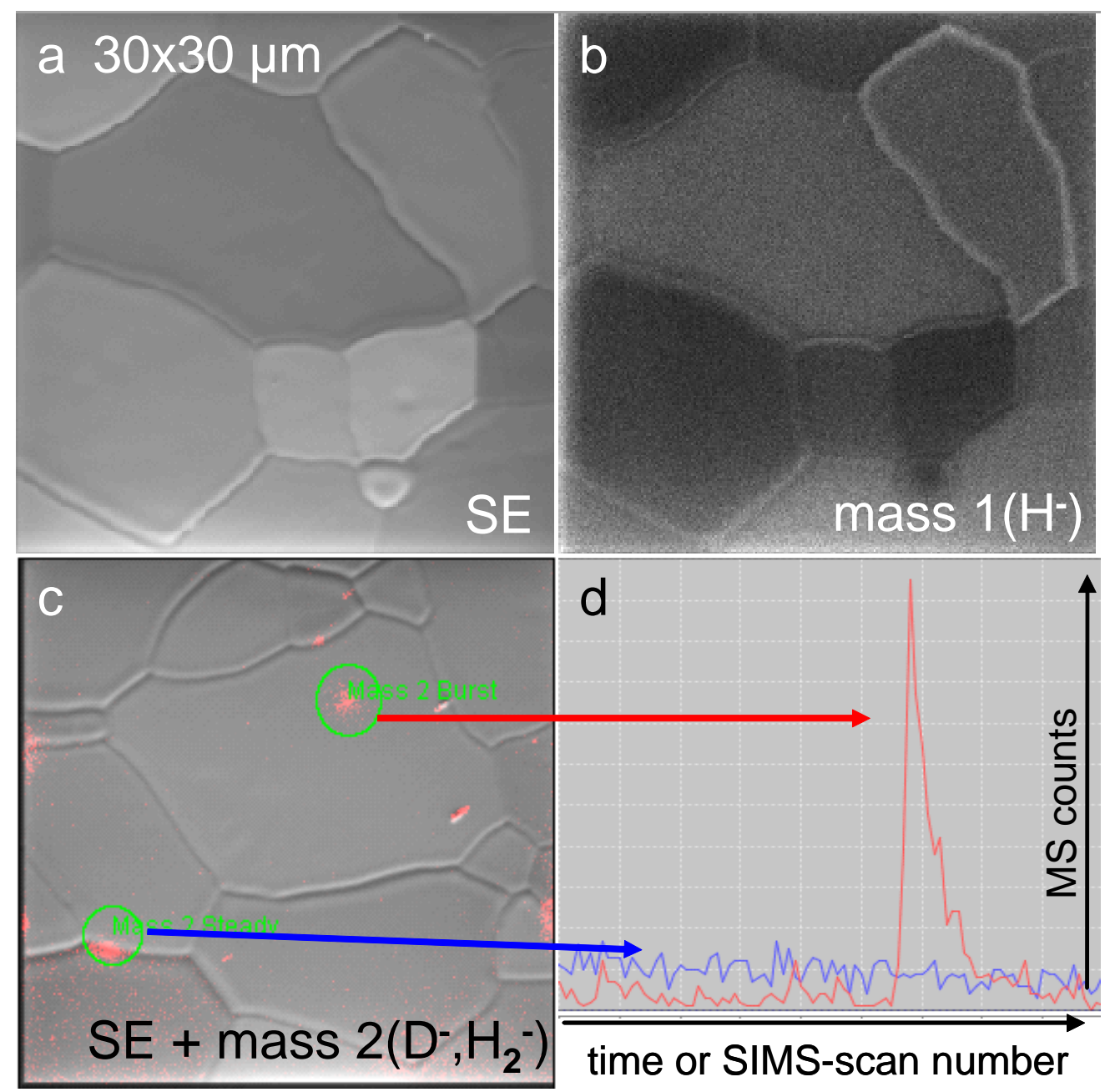

Fig 6 NanoSIMS analyses of a re-crystallized W sample loaded with D at 370 K. a) SE-image of sample surface, b) mass 1 signal $\left(\mathrm{H}^{-}\right)$image of the surface. Bright areas show $\mathrm{H}$ accumulation at grain boundaries. c) SE-image of an other area on the sample superimposed with the mass $2\left(\mathrm{D}^{-}\right.$or $\left.\mathrm{H}_{2}^{-}\right)$signal intensity integrated over all scan-cycles of SIMS. d) The diagram shows the mass 2 signals corresponding to the areas marked in c) resolved by scan cycle. There are spots at grain boundaries which show continuous $\mathrm{D}^{-}$emission and intra-grain spots which show time limited gas bursts with a decay as it is typical for the opening of gas filled pores. 